\title{
President's Cancer Panel
}

National Cancer Institute

\section{Source}

National Cancer Institute. President's Cancer Panel. NCI Thesaurus. Code C19163.

Consists of three persons appointed by the President, who by virtue of their training, experience, and background are exceptionally qualified to appraise the National Cancer Program. Two of the members of the Panel are disting uished scientists or physicians. Members are appointed for three-year terms. Established by Congress, December 23, 1971. 